\title{
Guideline about Antenatal Care for Pregnant Women at Damietta City
}

1Prof. Dr .Nawal Mahmoud Soliman: 2Dr.Mona Abdul El Sabour Hassan; 3Dr.

\author{
Reda Ibrahim Elmowafy : 4Badria El- Sharkawy Mohamed
}

1Professor of Community Health Nursing Faculty of Nursing Ain Shams University ; 2Assistant Professor of Family and Community Health Nursing Faculty of Nursing PortSaid University; 3Lecturer of Family\& Community Health Nursing Faculty of Nursing

Port Said 4University; Bsc. Nursing ,Tanta University.

\begin{abstract}
Background: In Egypt more than 2500 mothers die every year from problems related to pregnancy and childbirth, leaving behind 200 motherless newborns. These deaths, can be avoided if mothers have proper information about access to pregnancy care. Maternal mortality in Egypt may be due to no or poor antenatal care, delay in seeking medical care, unwanted pregnancy, substandard care from team/ general practitioner and lack of blood bank. Aim of study determines guideline about antenatal care for pregnant women in Damietta City. Quasi-experimental design was utilized in this study. The study Sample The sample of this study consisted of 93 women from the total number 500 pregnant women attending all Maternal and Child Health Centers $(\mathrm{MCH})$ at Damietta city according to inclusion criteria. The data were collected using two tools: The $1^{\text {st }}$ tool: Interview Questionnaire to assess knowledge and practices of pregnant women about antenatal care, the $2^{\text {nd }}$ tool was opinionnaire of pregnant women about booklet. The results of this study showed that, the total mean scores of knowledge of the studied sample in pre-test was $(25.61 \pm 6.43)$, after implementation of the guideline, it raised to be $(51.26 \pm 3.70)$. While the total mean score of practice in pre-test was (16.28 \pm 5.26$)$, raised in post-test to be (29.65 \pm 2.43$)$. Moreover a highly statistical significant differences were detected between pre and post test as regard knowledge and practice where $\mathrm{p} \leq 0.001$. The conclusion of this study was implementation of guideline about antenatal care improved pregnant women knowledge and practices about antenatal care. The study recommended that Based on the present findings, It was recommended the following. Provision of posters \& booklets about antenatal care within the Maternal and Child Health Centers $(\mathrm{MCH})$ available to see by pregnant women. Further research about different methods for maternal care education.
\end{abstract}

Key Words: Pregnant women, Informational guideline, Antenatal care. 


\section{INTRODUCTION}

Antenatal care defined as "care before birth" It is a care provided to improve the health of the pregnant woman and her baby by monitoring the progress of the pregnancy, detecting, managing any problems and helping them make a smooth transition to labor and delivery (Mansour and Amin, 2012).

Antenatal care (ANC) defined as the care a woman receives throughout her pregnancy in order to ensure that both the mother and child remain healthy. A healthy diet and lifestyle during pregnancy is important for the development of a healthy baby and may have longterm beneficial effects on the health of the child. Proper ANC is one of the important ways in reducing maternal and child morbidity and mortality. Unfortunately, many women in developing countries do not receive such care. Understanding maternal knowledge and practices of the community regarding care during pregnancy and delivery are required for program implementation (Yang et al., 2010).

In Africa each year, 30 million women's become pregnant, and 18 million give birth at home without skilled care from a trained health professional. Every year over 250,000 African women die because of complication related to pregnancy and childbirth, and four million African women have non-fatal complication of pregnancy. Globally, about 3 million newborn babies die in the first four weeks of life and there are also 3 million stillbirths. Africa accounts for $11 \%$ of world's population but $25 \%$ of all newborn deaths (Izugbara et al., 2016).

Every year the WHO estimates that worldwide around 536,000 women die from complications of pregnancy and childbirth. At least 7 million women who survive childbirth suffer serious long - term health problems, and a further 50 million women suffer some adverse health consequences after childbirth .The majority of these complication occur in developing countries (Charlotta et al, 2013).

Antenatal care is key entry point for a pregnant women to receive a broad range of health promotion and preventive health services including knowledge about healthy practices during pregnancy, and nutritional support, in addition to prevention and treatment of anemia, diagnosis and treatment of other diseases and tetanus toxoid immunization, routine antenatal care can be provided at both the household and primary health care level and helps to assure a link to higher levels of care when needed (Titaley et al., 2010).

Antenatal education interventions have an impact on the health of the pregnant woman as well as on the health and wellbeing of next generations in any country. They provide expecting mothers with information that enable them to identify potential warning signs of malfunction or abnormalities during pregnancy as well as strategies to adhere to prescribed treatments and referrals. It has been shown that approximately $80 \%$ of maternal mortality could be prevented if the affected mother had a timely access to the 
essential maternity and basic health-care services. Furthermore In an effort to improve health outcomes for mothers and their infants, nurses need to design relevant prenatal health educational methods when caring for pregnant women (Kaitlyn et al., 2011).

\section{Magnitude of the problem:}

According to Egypt Demography and health Survey, slightly more than one quarter of Egyptian pregnant women do not receive antenatal care. However, among those who receive antenatal care only one third of them received advised about signs of obstetric complications and where and when to seek medical assistance. In Egypt, maternal mortality ratio has declined dramatically from 174/100000 live births in1992-1993 to $67.6 / 100000$ live births in 2005 , a further decline to $44.6 / 100000$ was also reported by 2009. The available Egyptian researches do not assess women's satisfaction and perception of different aspects of quality of care with specification to the different components of antenatal care (Montasser et al, 2012).

Antenatal care defined as an early and regular checkups by medical providers are very important in assessing the physical status and early detection of complications woman may experience during pregnancy, Prenatal care is not limited to medical care, it also includes education and counseling about how to handle several different aspects of pregnancy, such as nutrition and physical activity, what to expect from and how to prepare for the birth experience itself, and basic parenting skills (National Institute of Child Health \& Human Development, 2010).

It has been reported that most of the maternal deaths are avoidable as the interventions to prevent or manage the most common complications. Furthermore, many of these complications can be prevented, detected, or treated during antenatal care visits with trained health workers (Hogan, 2010). In the developing world nearly $70 \%$ pregnant women have at least one antenatal care visit, and the majority of women presenting for any antenatal care have at least four visits (Beeckman et al., 2011).

So, this study was carried out to assess the knowledge and practices of pregnant women regarding antenatal care, design, implement and evaluate guideline focusing on health promotion of the pregnant women.

\section{AIM OF STUDY:}

The aim of this study is to determine guideline about antenatal care for pregnant women in Damietta City through:

1- Assess the knowledge and practices of pregnant women regarding antenatal care to before and after implementation of guideline.

2- Design and implement a guideline about antenatal care for pregnant women according to their needs.

\section{SUBJECTS AND METHOD:}

\section{Research design}

Quasi-experimental design was utilized in this study. 


\section{Setting:}

This study was carried out in a Maternal and Child Health Centers (MCH) in the Damietta City which consists of five Maternal and Child Health Centers $(\mathrm{MCH})$ representing All MCH centers, namely: First Hadary Center, Second Hadary Center, Third Hadary Center, Fourth Hadary Center, and El Montazah Hadary Center.

\section{Target population:}

The Target population for this study was pregnant women attending in the pre mentioned setting.

\section{Population sample:}

Total attending in $\mathrm{MCH}$ centers were 120, 100, 110, 80, 90 pregnant women (500 pregnant women in 2013) in the pre-mentioned centers respectively.

\section{Sample size :}

The sample of this study consisted of 93 women from the total number 500 pregnant women attending all Maternal and Child Health Centers $(\mathrm{MCH})$ at Damietta city according to inclusion criteria

The sample size for pregnant women calculated using the following equation:

$$
\mathrm{N}=\frac{\mathrm{p}(1-\mathrm{p}) \cdot \mathrm{Z2}}{\mathrm{D} 2}
$$

(Kish and Leslie, 1965).

$\mathrm{P}=$ estimated prevalence of antenatal care $(0.7)$

$\mathrm{Z}=1.96$ (confidence level 95\%)

$\mathrm{D}=$ the width of the desired sample confidence interval $=0.098$

D2 $=(0.098) 2=0.009604$

$\mathrm{Z} 2=(1.96) 2=3.8416$

$$
N=\frac{p(1-p) . Z 2}{D 2}
$$

$$
\mathrm{N}=\frac{0.7(1-0.7) 3.8416}{0.009604}=84
$$

With expected drop out rate $=10 \%$ the sample size will be 93 women. 


\section{TOOLS:}

To achieve the purpose of this study, data were collected through using 2 tools which were developed by developed by the researcher, based on reviewing related literatures and experts' opinions, written in Arabic language in the form of multiple choice questions. It was divided into fourth parts and entitled the following items:

TOOL I: This includes fourth parts.

The first part: Included questions related to socio demographic data such as (age , level of education, work, hereditary diseases, number of children) (Questions, No. 1-6) and medical history such as presence of chronic disease (as heart disease, renal disease, , diabetes mellitus ) epilepsy, current use of medicines ....etc) (Questions, No. 8-9).

The second part: Medical history: Included questions related to obstetrical history: included (number of previous pregnancies, type of delivery, history of other than caesarean section, events such as live birth, still birth, abortion, birth weight of previous pregnancies, sex of the child, periods of exclusive breastfeeding previous special maternal complications, obstetrical operations and previous prenatal complication....etc) (Questions, No 10-17).

The third part: Included questions related to knowledge of pregnant women about antenatal care: includes (Meaning, component, importance, purposes, schedule, physical examination, investigation, immunization, Health promotion, medical and psychological intervention, risks during pregnancy, birth and emergency preparedness plan, signs of labor .etc). (Questions, No18-49).

The fourth part: Included questions related to Practices as stated by pregnant women about antenatal care: such as nutrition, exercise, medication, work, activities, management of minor discomfort of pregnancy, breast care and perineatal care (Questions, No50-69).

The scores of the pregnant women knowledge were calculated as follow correct answers were scored (1), wrong answers were scored (0) and unknown answers were scored (0). Each question answer was weighted according to the numbers of the given correct answer. Total knowledge score was calculated as the following: Satisfactory $\geq 60 \%$ of total knowledge grade, unsatisfactory $<60 \%$ of total knowledge grades. The scores of the pregnant women practice were calculated as follow correct answers were scored (1), wrong answers were scored (0) and unknown answers were scored (0). Each question answer was weighted according to the numbers of the given correct answer. Total practice score was calculated as the following: Satisfactory $\geq 60 \%$ of total practice grades. And unsatisfactory $<60 \%$ of total practice grades.

\section{TOOL II:}

It was developed by the researcher to identify the studied women opinion about the guideline based on reviewing textbooks, related articles and research studies. An opinionnaire questionnaire was used to evaluate the guideline by the selected women: it 
included women opinion about degree of benefits, degree of understood, its clarity, if its answer their questions, its feasibility and simplicity (Questions, no1-8).

\section{Content Validity}

Validity was ascertained by a Jury consisting of five experts in the field of Community Health Nursing, Faculties of Nursing (Port Said University and Ain Shams University). Necessary modifications were done according to the experts' opinions.

\section{Reliability}

Reliability of the tools was done by using (test and retest) measurement and applied of time to be sure the consistency of answers. The reliability was assured by means of Cronbach's alpha; it indicated that the tool has a reliability of 0.987 .

\section{Pilot Study}

The pilot study was carried out on $10 \%$ of the studied pregnant women (10 pregnant women) in a Maternal and Child Health Centers (MCH) in the Damietta City to evaluate the reliability and applicability of tools and to estimate the proper time required for answering the questionnaire. They were excluded from the sample. Modification was done according to the results of pilot study.

\section{Field Work:}

The study conducted during the period from the beginning of October 2013 to the end of March 2014).

The study was constructed through the following four phases:

\section{Phase (1): Pre- test}

After obtaining the official permission to conduct the study and after finalization of the tools, the study sample was recruited. This was followed by collecting baseline data. Pretested questionnaire was administered to the study sample to assess their knowledge and practices regarding antenatal care, data collected from the pregnant women was performed during their visit Maternal and Child Health Centers $(\mathrm{MCH})$ were visited according to time schedule.

The researcher interviewed the pregnant women after introducing herself, took the oral consent from them to be recruited in the study and after explaining the aim of the study. For the pregnant women, the researcher distributed the structured Interview questionnaire to them after clear explaining the way to fill out. During the interview, the researcher read each item/question on data collection sheet and explained its meaning to the pregnant women. Then the pregnant women were asked to write down their answers. Each sheet lasted about 30 minutes to be filled. Confidentiality for all collected information was strictly assured. The pre- test took about two months from the beginning of October 2013 to the end of November 2013(1 day/week for each center) each center obtained the eight day through the eight weeks) from Sunday to Thursday. 


\section{Phase (II): Guideline Planning}

Based on the information obtained from initial assessment, in addition to literature, the researcher designed the guideline under the guidance of the supervisors. Its main objective: was to evaluate guideline about antenatal care for pregnant women in Damietta City. A guideline was developed for pregnant women and it covered all items related to antenatal care. It included the following items: Meaning of Antenatal care, Objectives of antenatal car booklet, Importance of antenatal care, Components of antenatal care, Nutrition during pregnancy period, Medication during pregnancy period, Health promotion during pregnancy period, Management of common discomforts of pregnancy, Danger signs of pregnancy period, Sign \& Symptoms of delivery, and Importance of breastfeeding for Mother \& baby.

The guideline was written in simple Arabic language with different illustrated colored pictures to enhance the learning process and facilitate pregnant women' understanding. After developing of the guideline, it was revised by a panel of five experts in the field of community health nursing, faculties of nursing (Port Said University, and Ain Shams University).

\section{Phase (III): Implementation of Guideline}

The guideline was carried out in a Maternal and Child Health Centers (MCH) in the Damietta City. The subjects were divided into small groups (5 groups), three groups contain 19 of participants and two groups contain 18 of participants. For interviewing women, the researcher depended on coordination with Maternal and Child Health Centers $(\mathrm{MCH})$ manager in gaining information about visits' pregnant women and times of work. In addition, Coordination was done with antenatal care nurses to enable the researcher to interview pregnant women.

The implementation was conducted through 40 sessions; each group obtained the eight sessions through the eight weeks ( 1 session /week for each center), each session took about two hour. The total allocated time for achieving guideline objectives for the five groups was 80 hours ( 5 groups $\times 8$ weeks $\times 2$ hours). At the beginning of the first session, an orientation to the aim of the study and the goals of the guideline took place. Also, women were oriented about the phases of the study and the guideline sessions (time, duration, place, and contents). The researcher stressed on the importance of continuous attendance and active participation.

Different teaching and learning methods were used during the sessions which included; interactive lecture, group discussion, demonstration \& re-demonstration, instructional media included data show, pictures, blackboard and printed handout. The guideline was presented in clear and concise form to be used as memorial reference. Each session started by a summary of the previous session and objectives of the new session, using a very simple language that suits the level of pregnant women without ignoring motivation and reinforcement techniques. Women were allowed to ask any interpretation, elaboration or 
explanation of any item included in the guideline. The implementation of guideline took about two months (from December 2013 till the end of January 2014) each center obtained the eight day through the eight weeks (1 day/week for each center) from Sunday to Thursday.

\section{Phase (IV): Evaluation through Post- test}

After implementation of the guideline, post test were done to evaluate the effect of it; the post test was done immediately by end of the guideline using the same tool which was used in the pre test. Using an opinionnaire questionnaire which was used in evaluate the guideline by the selected women. The post -test took about two months from the beginning of February2014 till the end of March 2014 (1 day/week for each center) each center obtained the eight day through the eight weeks) from Sunday to Thursday.

\section{Ethical Consideration:}

An official permission was taken from the dean of the faculty of nursing in Port Said University to the directors of the studied Maternal and Child Health Centers in Damietta City, to ensure their cooperation and permission. All relevant ethical aspects were considered for ensuring pregnant women's privacy and confidentiality of the collected data during the study. The purpose of the study was explained to each pregnant woman, and then an oral consent for participation in the study was obtained from each one of them. Voluntary participation and right to refuse to participate in the study and withdrawn at any time was emphasized to pregnant women.

\section{Statistical Analysis:}

After completion of data collection, the data were organized and tabulated, statistically analyzed using Data entry was done using Epi-Info 6.04 computer software package, while statistical analysis was done using SPSS 14.0 statistical software package. Data were presented using descriptive statistics in the form of frequencies and percentages for qualitative variables, and means and standard deviations for quantitative variables

\section{The following statistical measures were used:}

Paired $(\mathrm{t})$ test was used to compare mean score between both studied variables. The $\mathrm{p}$ value is the degree of significant and using the correlation ( $r$ ) test. The p-value is the probability that an observed difference is due to chance and not a true difference. A significant level value was considered when $\mathrm{p}$-value $\leq 0.05$ and a highly significant level value was considered when $\mathrm{p}$-value $\leq 0.001$, while $\mathrm{p}$-value $>0.05$ indicates nonsignificant results. . a Predictors: (Constant), gravida, family income, age, gestational, knowledge pre, occupation, family number, education, home room number, b Dependent Variable: knowledge post $r$-square $=0.350 \quad$ Model ANOVA: $F=1.28-----p>0.05$. a. Predictors: (Constant), gravida, family income, age, practice pre, occupation, gestational, family number, education, home room number b. Dependent Variable: practice post r-square $=0.215$ Model ANOVA: F=.445----- $\mathrm{p}>0.05$ 


\section{RESULTS:}

Table (1): indicats that the age of the study sample ranged from less than 20 years to more than 30 years with a mean of $(29.43 \pm 5.62)$, more than one third $(36.6 \%)$ of the study had secondary education, the majority $(80.6 \%)$ of the study sample were house wife, more than two thirds (69.9\%) of the study sample mentioned that their income was not enough.

Table (3): shows that as regards benefits of the intervention guideline, that more than half $(57.0 \%)$ of the study sample reported that the intervention guideline provide all information they need, that all of the studied sample $100 \%$ mentioned that the guideline is completely understood to the antenatal care, clear, answering their questions regarding antenatal care, simplicity and applicable to the antenatal care.

Table (4) : indicats that there was no statistical significant association was detected between knowledge and practice pre and post intervention. And There were no statistical significant relation between knowledge, practice in pre and post intervention and age, gestational and gravida of the studied sample

Figer (1): reavels that The majority of the studied sample $(90.30 \%)$ in pre-test had unsatisfactory knowledge scores. While the most of studied sample in post-test $(91.40 \%)$ had satisfactory knowledge scores.

Figer (2): The majority $(80.6 \%)$ of the studied sample in pre-test had unsatisfactory practice scores. While, the most of the studied sample in post-test (93.50\%) had satisfactory practice scores. 
Table (1): Distribution of Socio-demographic characteristics of the studied sample ( $n=93)$

\begin{tabular}{|l|c|c|}
\hline Variable & Frequency & \% \\
\hline Age (years) & 22 & 23.7 \\
$<20$ & 57 & 61.3 \\
$20-$ & 14 & 15.1 \\
$30+$ & $29.43 \pm 5.62$ & \\
\hline Mean \pm SD & & \\
& 2 & 2.2 \\
\hline Education & 34 & 36.6 \\
Read and write & 24 & 25.8 \\
Secondary education & 33 & 35.5 \\
Technical education & 18 & 19.4 \\
University education & 75 & 80.6 \\
\hline Occupation & & \\
Employee & & 69.9 \\
House wife & 65 & 30.1 \\
\hline Family income & 28 & \\
Not enough & & \\
Enough & & \\
\end{tabular}


Table (2): Distribution of the studied sample according their obstetric history $(n=93)$.

\begin{tabular}{|l|c|c|}
\hline \multicolumn{1}{|c|}{ Variable } & Frequency & \% \\
\hline Gestational age & 3 & 3.2 \\
First trimester & 46 & 49.5 \\
Second trimester & 44 & 47.3 \\
Third trimester & & \\
\hline Gravida & 41 & 44.1 \\
First & 43 & 46.2 \\
Second & 9 & 9.7 \\
Multi gravid & & \\
Method of previous delivery & 41 & 44.1 \\
No previous delivery & 33 & 38.7 \\
Normal vaginal delivery & 16 & 17.2 \\
Cesarean delivery & & \\
\hline Previous pregnancy & & 38.5 \\
complication (n=52) & 32 & 61.5 \\
Present & & \\
No present & & 28.8 \\
\hline Previous delivery \\
complication (n=52) & 15 & 71.2 \\
Present & 37 & \\
No present & & \\
\hline Number of live children & & \\
(n=52) & & \\
one to less than three & & \\
More than three & & \\
\hline
\end{tabular}


Table (3): Distribution of the studied sample in relation to benefits of the intervention of guideline.

\begin{tabular}{|l|c|c|}
\hline \multicolumn{1}{|c|}{ Variable } & No & $\%$ \\
\hline Benefits of guidelines & 53 & 57.0 \\
Provide all information I need & 36 & 38.7 \\
Provide Correct information & 4 & 4.3 \\
Provide Complete information & 93 & 100 \\
\hline Degree of understanding guidelines & 93 & 100 \\
Complete understood & 0 & 0 \\
\hline Degree of clarity of guidelines & & \\
Clear & 93 & 100 \\
Not clear & 0 & 0 \\
\hline Role of guideline in answering mothers & 75 & 80.6 \\
questions & 0 & 19.4 \\
Answer all questions & & 0 \\
Answer part of questions & & \\
\hline Degree of guidelines simplicity & & \\
Simple & & \\
Complex & & \\
\hline Degree of applying guidelines instructions & & \\
Completely apply & & \\
Partially apply & & \\
\hline
\end{tabular}


Table (4): Correlation between knowledge and practices of the studied sample and their age, gestational\& gravida pre and post intervention.

\begin{tabular}{|l|l|l|l|l|l|l|}
\hline Variable & Gravid & \multicolumn{3}{l}{ Gestational } & Age & \\
\hline & $\mathbf{P}$ & r & P & r & P & r \\
\hline & & & & & & \\
Knowledge pre & 0.96 & 0.01 & 0.22 & -0.13 & 0.12 & 0.16 \\
Knowledge post & 0.20 & 0.13 & 0.33 & -0.10 & 0.32 & -0.11 \\
& & & & & & \\
Practice pre & 0.75 & -0.03 & 0.02 & $-0.24^{*}$ & 0.85 & -0.02 \\
Practice post & 0.97 & -0.00 & 0.63 & 0.05 & 0.74 & 0.03 \\
\hline
\end{tabular}

* Correlation is significant at the 0.05 level (2-tailed).

Figure (1): Total knowledge scores pre and post-test

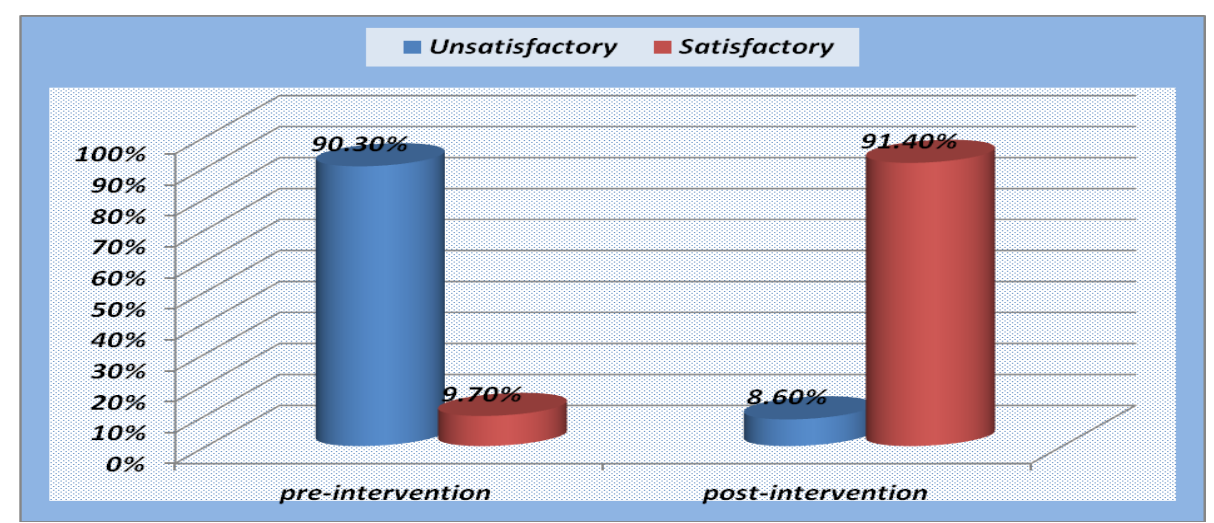

Satisfactory $\geq 60 \%$ of total knowledge grades. Unsatisfactory $<60 \%$ of total knowledge grades

Figure (2): Total practices scores pre and post-test

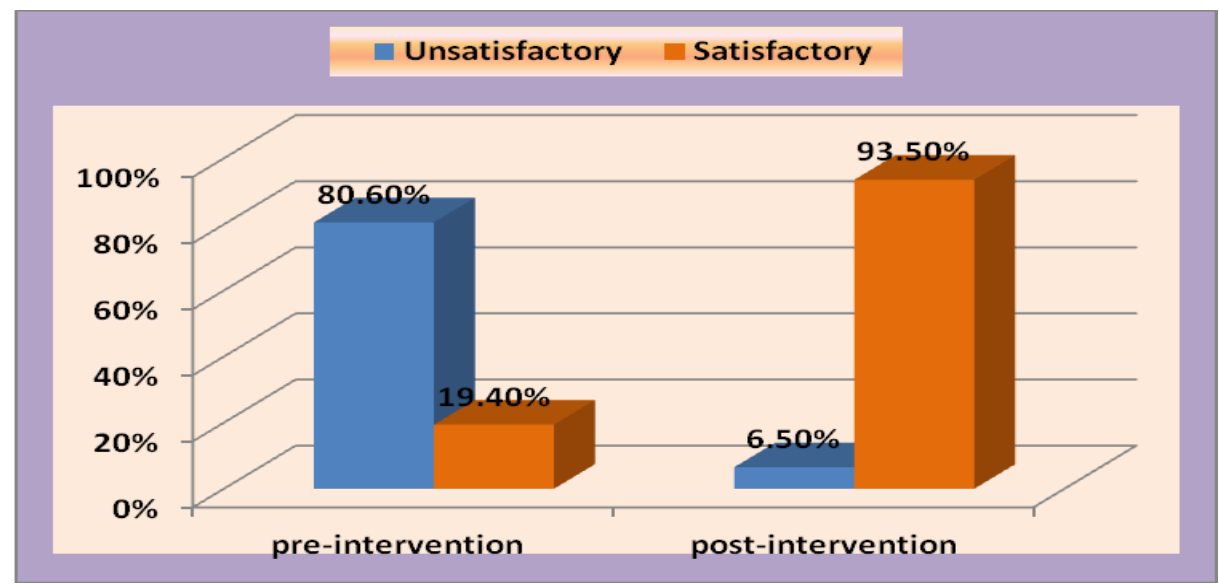

Satisfactory $\geq 60 \%$ of total knowledge grades. Unsatisfactory $<60 \%$ of total knowledge grades. 


\section{DISCUSSION:}

Antenatal care (ANC) is the key entry point of a pregnant woman to receive broad range of health promotion and preventive services which promote the health of the mother and the baby. Proper ANC is one of the important ways in reducing maternal and child morbidity and mortality. Understanding maternal knowledge and practices of the community regarding care during pregnancy and delivery are required for improvement of their health. So, the aim of the present study is to evaluate guideline about antenatal care for pregnant women in Damietta city (Montasser et al, 2012).

According to the result of the present study, the age of the studied sample ranged from less than 20 years to more than 30 years, More than one third of them had secondary education, and this is expected because it is the common and ideal age of childbearing. This resulting disagreement with Soliman,(2015) revealed that the age of the majority of the pregnant women ranged from 20 years to less than 35 years old, more than half of them had secondary education and less than one fifth of them had university education. The majority of the present study was house wife. This is anticipated because working women may not find the chance to visit the maternal and child health centre especially during working hours. This result is congruent with the results of Habib et al,( 2011). Also, about one half of the present study mentioned that they were in the second trimester. These findings may be due to lack of clients' knowledge about the importance of ANC, This result is contrary to Mansour and Amin(2012), in Al-Madinah mentioned that More than one third of women started ante natal care at The third trimester of pregnancy. Also about half of the studied sample were in the second gravid, almost less than half of them had no previous delivery, this resulting disagreement with Laxmi Kumar, (2014) in India, who mentioned that Most of the pregnant women 31(51.7\%) were primi-gravida and $5(8.3 \%)$ were grand multi-gravida, Moreover, nearly one thirds of them had no previous pregnancy or delivery complication, and the majority of them had one to less than three live children.

Results shows that total knowledge and practice of the pregnant women were improved after implementation of guideline about antenatal care ,moreover, most of the studied women reported that they found the informational guideline provide them with sufficient knowledge and practices regarding antenatal care This results is in the same line with Sanayaima et al, (2013) who reported that, to improve community awareness on ANC, information, education and communication activities, we should be increased ANC through community campaign and mass media. In addition, Ankur, (2010) showed that, educational intervention program can bring about a desirable change in the knowledge among adolescent girls regarding reproductive health. In contrast Laxmi Kumar, (2014) found that, most of the pregnant women had not exposed to any health education and most of the pregnant women got information through media. 
According the research hypothesis they was improvement in hypothesis, Provision of guideline about antenatal care improved pregnant women knowledge and practices and this result may be due to the utilization of the guideline by the mothers as they reported in the study results. This result is in the same line with Agbede et al, (2015) who found that, corroborative intervention, directed at creating more awareness on maternal reproductive health and providing necessary education for pregnant women should be encouraged. Moreover, Nitanjali \& Jyoti, (2013) in India, reported that, the Self instructional module (SIM) on minor ailments of pregnancy and its home remedies was effective. Also, Laxmi Kumar, (2014) in India, concluded that, Self Instructional module ${ }^{\text {ee }}$ (SIM) was effective to increase the knowledge of antenatal mothers regarding minor ailments and their remedial measures. Furthermore, in the study carried by Ojong et al, (2015) in Nigeria, they reported that, majority of pregnant women had good knowledge of FANC while minority had poor knowledge of focused antenatal care (FANC). This result is supported by Yang et al, (2010) in their study on factors affecting utilization of FANC who discovered respondents high level of knowledge on focused antenatal care (FANC) as a factor affecting utilization of focused antenatal care (FANC). Also in line with the above, Akpan-Nnah, (2011) in a study on knowledge and attitude toward focused antenatal care (FANC) discovered that 77(64.1\%) of respondents had good knowledge of focused antenatal care (FANC). Rosalia and Muhammad, (2011) in Nigeria also are in support of the above.

\section{CONCLUSION:}

The study concluded that a highly statistical significant improvement were detected in all areas, and total mean score of the women knowledge and practices from pre to post guideline intervention. All of the studied sample $100 \%$ mentioned that the guideline is completely understood to the antenatal care, clear, answering their questions regarding antenatal care, simplicity and applicable to the antenatal care. Improvement in research hypothesis, guideline about antenatal care improved pregnant women knowledge and practices

\section{RECOMMENDATIONS:}

On the support of the current study findings, it is recommended that, There is a need to motivate women to utilize maternal care services which are freely available in all the government health set up. Applying of health education for all pregnant women about schedule of antenatal care, immunization, health promotion, nutrition, risks during pregnancy, management of minor discomfort of pregnancy, breastfeeding, breast care and perineal care...etc. Provision of posters \& booklets about antenatal care within the Maternal and Child Health Centers (MCH) available to see by pregnant women. Further research about different and modern methods for maternal care education

\section{REFERENCES:}

Agbede, P.E. Omeonu \& J.O. Kio. Influence of Clinic-Based Health Education on Pregnant Women's Knowledge and Attitudes in Relation to Pregnancy 
Management:Evidence from Ogun State, Nigeria, Global Journal of Medical Research: E Gynecology and Obstetrics 2015;15 ( 1 ) :4

Akpan-Nnah, E. M. (2011): Knowledge and attitude of pregnant women towards focused antenatal care in General Hospital, Ikot Ekpene, Akwa Ibom State, International Professional Nursing Journal. 9(1): 96 - 104.

Ankur Barua(2010):Effectiveness of Reproductive Health Education in Adolescent, Rural School Girls of Udupi Taluk, Karnataka JIMSA October - December 2010: 23 (4):6

Habib F, Hanafi $M$, El sagheer A. antenatal care in primary health care centers in Madina, Saudi Arabia, 2009: a cross-sectional study. Eastern Mediterranean Health Journal 2011; 17(3):196-202.

Hogan MC, Foreman KJ, Naghavi M, Ahn SY, Wang M, Makela SM, Lopez AD,Lozano R, Murray CJL.Maternal mortality for 181 countries, 1980-2008: a systematic analysis of progress towards Millennium Development Goal 5. The Lancet, 2010;375(1):609-23.

Izugbara, C.O., Wekesah, F. M. \& Adedini, S. AMaternal Health in Nigeria: A Situation Update. African Population and Health Research Center (APHRC), Nairobi, Kenya 2016

Laxmi Kumar. Effectiveness of 'Self Instructional Module' (SIM) On the Level of Knowledge Regarding Selected Minor Ailments and Their Remedial Measures among Pregnant Women, IOSR Journal of Nursing and Health Science (IOSR-JNHS) e-ISSN: 2320-1959. ISSN: 2320-1940 Ver. IV 2014; 3(1):32-38

Kish, Leslie. (1965): Survey Sampling. New York: John Wiley and Sons, Inc.

Mansour and Amin.(2012): Women's Satisfaction with the Quality ofAntenatal Care at the Primary Health Care Centers in Al-Madinah Al-Menawarh, KSA. Life Sci J, 2012;9(4):4291-4299

Montasser N, Helal R, Megahed W, Amin S,Saad A, Ibrahim T, Abd Elmoneem H.(2012): Egyptian Women's Satisfaction and Perception of Antenatal Care. International Journal of Tropical Disease \& Health 2012; 2(2): 145-156

National Institute of Child Health \& Human Development. (2010): Care before and during pregnancy: Prenatal care. Retrieved October 13, 2011, from

http://www.nichd.nih.gov/womenshealth/research/preg birth/prenatal_care.cfm

Nitanjali Patil1, Jyoti Salunkhe.(2013): Assessment of Knowledge on Minor Ailments of Pregnancy and Home Remedies International Journal of Science and Research (IJSR) ISSN (Online): 2319-7064 Index Copernicus Value : 6.14 | Impact Factor 2013; 4.438 
Ojong, Idang N, Uga Adaora, L. \& Chiotu, Catherine N.(2015): Knowledge and attitude of pregnant women towards focused antenatal care services in University of calabar teaching hospital, Calabar, Cross Riverstate,Nigeria, International Journal of Midwife and Health Related Cases2015;.1(1):14-23

Otaiby TAI, Jradi H, Bawazir A. (2013): Antenatal Education: An assessment of Pregnant Women Knowledge and Preferences in Saudi Arabia. J Women's Health Care 2013;2 (1): 139.

Rashad WA, Essa RM.(2010): Women's awareness of danger signs of obstetrics complications. J Am Sci 2010; 6:1299-1306.

Rosalia, A. M. \& Muhammad, J. Knowledge, attitude and practices on antenatal care among orang asli women in Jrempel, Nigeria Sembelian. Malaysian. Journal of public health medicine $2011 ; 11(2), 13-21$.

Sanayaima Devi, Jalina Laishram, Usha Devi Thounaojam, Jina Panmei, Salona Mukhia. Knowledge and Practice of Ante-natal Carein an Urban Area, Indian Medical Gazette - March 2013

Soliman. F. Satisfaction of Rural Pregnant Women as Quality Indicator of Provided Antenatal Care, International Journal of Scientific and Research Publications, 2015; $5(3): 2250-3153$

Titaley, M. Dible, C. Roberts. Factors associated with underutilization ofantenatal care services in Indonesia: results of Indonesia Demographic and Health Survey 2002/2003 and 2007, BMC Public Health, 2010; 10 (1): 485.

Yang Ye, Y., Yashida, H. R. \& Junichi, S. Factors Affecting Utilisation of Antenatal Care Services among Women in Khan District, Xrengkhouang Province. Nagoya Journal of Medical Sciences 2010; 72(1): 23-33. 


\section{دليل معرفي للعناية بالسيدات أثناء فترة الحمل بمدينة دمياط}

بلرية الثرقاوي محمد رضوان، أ.د/ نوال محمود سليمانـ د/ مني عبد الصبور حسن- د/ رضا ابراهيم الموافي

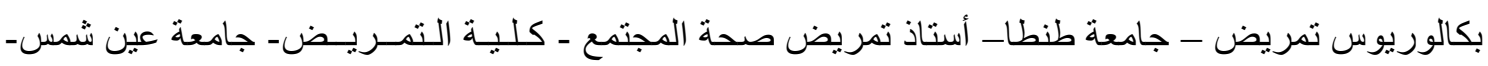
أستاذ مساعد تمريض صحة الاسرة و المجتمع-- كليـة التمريض- جـامـــة بورسعيد ـ مدرس تمريض صحة

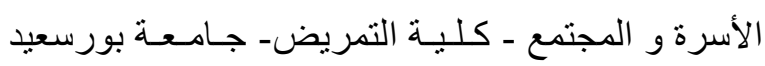

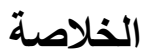

في مصر يموت كل عام اكثر من . . T ام من المشاكل المتعلقة بالحمل و الو لادة ، تاركين ورائهم .. . طفل حديثي

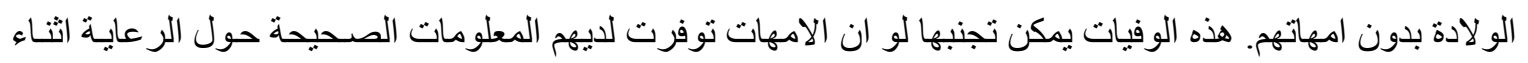
فترة الحمل. و كان الهدف مـن خـلال هذة الدر اسـة هو تقييم دليل معرفي للعناية بالسيدات اثثـاء فترة الحمل بمدينة دمياط. و اثتملت هذة الدر اسة التجريية على ثُلاثة و تسعون سيدة حامل فى خمس مر اكز (صحة الام و الطفل) التي

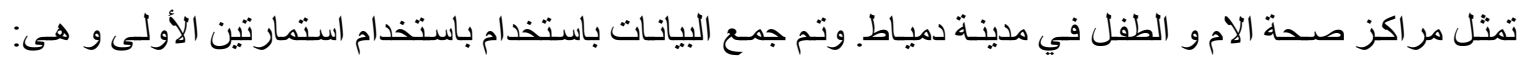

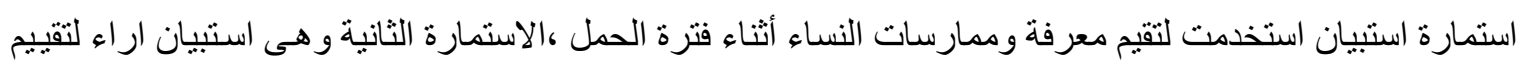

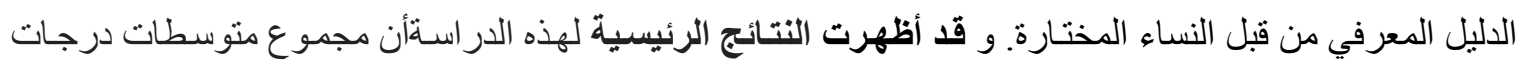

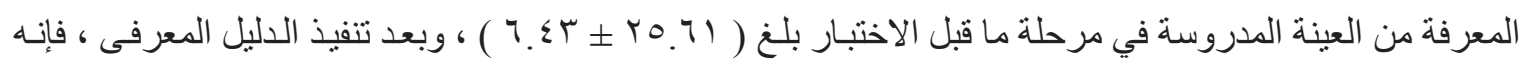

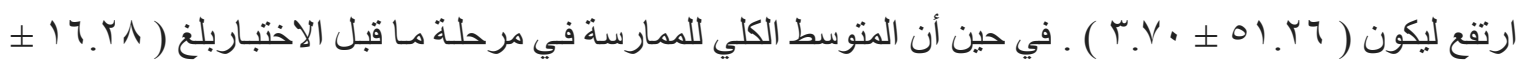

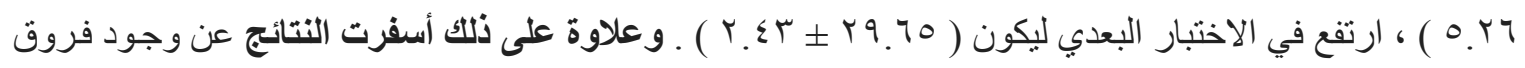

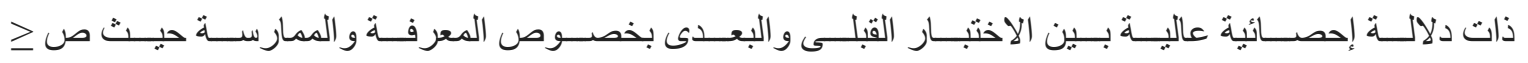
1 . . • الخلاصة :خلصت الدر اسة الى أن الدليل المعرفى يحسن معرفة و ممارسات السيدات أثناء فترة الحمل ـ بنـاء

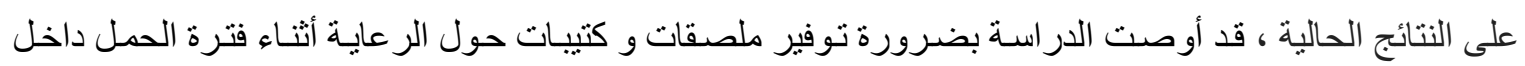
مر اكز رعاية الأمومة و الطفولة ( صحة الأم و الطفل ) المتاحةالتى تساعدالسيدات الحو امل على معرفة الر عايـة أثناء فترة الحمل. كما أوصت الدر اسة أيضا أخيرا بضرورة وجود در اسلهات مستقبلية خاصـة بطرق مختلفة للتثقيف العناية

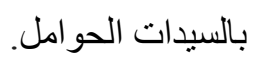

الكلمات المرشدة : العناية أثناء فترة الحمل،مر اكز تنظيم الأسرة ، دليل معرفى للعناية أثناء فترة الحمل 